\title{
2015 AECT International Convention Summary
}

\author{
Donovan R. Walling ${ }^{1}$
}

Published online: 23 February 2016

(C) Association for Educational Communications \& Technology 2016

The 2015 AECT International Convention commenced on a bright Indiana autumn day, Tuesday, November 3, at the Indianapolis Hyatt Regency Hotel, with a flurry of preconvention workshops. The theme this year was "Accelerate Learning: Racing into the Future," a nod to Indianapolis as home to the famous Indy 500 auto race. No article could do justice to the wealth of professional development workshops, sessions, and other activities. The purpose of this summary is merely to offer a sampling of highlights, looking particularly at the keynote and presidential sessions, which mirrored in their diversity the wide range of topics represented across the array of conference events.

The convention proper kicked off on Wednesday afternoon, with the start of the roster of regular sessions. The first presidential session was "Emerging Technologies Showcase," which afforded attendees the opportunity not only to become aware of the latest technologies, but also to share with each other different ways they are using these emerging technologies. A large number of innovative AECT members showcased technologies, ranging from new apps and assistive devices to augmented and virtual reality software and strategies.

Many sessions, of course, take place simultaneously and so choosing which to attend can be challenging. At the same time as the showcase, a new AECT partner, Uchida Yoko Global, presented "Effective Implementation of Real Time Feedback." Uchida Yoko Global Limited was formed in 2011, when its parent company, Uchida Yoko Co., Ltd., approved a plan to separate its Overseas Department into a new

Donovan R. Walling

drwalling@gmail.com

1 Bloomington, IN, USA company. The mission of Uchida Yoko Global Limited is to bring products to Japan from the World as well as to provide products from Japan to the World. Uchida Yoko has been a leading Japanese educational equipment supplier for more than half a century. The session included live video and hands-on use of an individual "EduClick" handheld feedback device, a simple yet highly versatile piece of classroom technology.

"Blurred Lines: Preparing K-12 Instructional Technologists and School Librarians for Educational Entrepreneurship" followed these sessions. This allowed presenters from several universities to discuss a range of topics, such as professional development in preservice practicums and the building of knowledge, skills, and dispositions to the reinvention of school library spaces and educational practices.

Wednesday afternoon's final presidential session, led by Larry Johnson, CEO of the New Media Consortium (NMC), was titled "In Search of Uncommon Wisdom." The premise of this discussion was that "virtually every assumption we have about the use of technology in education-our common wisdom - is based on how we have done things in the past. What we see coming shares little in common with the technologies, networks, software, or systems of today. Our common wisdom won't be enough. We need uncommon wisdom." Johnson connected concepts of time and space to notions of the library, the university, and technology for today and tomorrow.

A high point of Wednesday afternoon was the First General Session, which included the official passing of the presidential gavel from Rob Branch to Kay Persichitte and the keynote presentation, "Slow and Fast Learning with Contemporary Digital Technologies," given by Gráinne Conole, who took a new post at the University of Bath Spa in Britain in February of 2015 Previously, she was professor of learning innovation and director of the Institute of Learning Innovation at the 
University of Leicester. She also is the author of Designing for Learning in an Open World, recently published by Springer. Conole discussed foreseeable as well as probable changes and innovations that will influence learning and particularly elearning. In concluding, she posed an interesting question about whether we ought to encourage "slow education," that is, a more focused, thoughtfully paced approach to teaching and learning à la the slow food movement.

Incidentally, at every AECT International Convention a number of individuals are recognized for their achievements and contributions to the association and the profession. This year, for example, Danilo Baylen, International Division immediate past president, was honored at the International Visual Literacy Association (IVLA) gala dinner with the Education Award. ILVA is an AECT affiliate. Baylen coedited with Adriana D'Alba Essentials of Teaching and Integrating Visual and Media Literacy, published by Springer. The book includes chapters written by other AECT members. The award recognized Danilo's dedication to visual literacy and education.

Thursday afternoon's roster of presidential sessions began with "Using Games in the Classroom: Reports from Three Perspectives." Presenters Alison Carr-Chellman and Jason A. Engerman, Penn State University, shared results from a multi-phase study that looked at what boys learn when they game and discussed implications for classroom practice. CarrChellman's son Jules, a 13-year-old eighth-grader, was included in the panel and described his experience in a public, project-based charter school. The speakers spoke about the disparities in learning culture between boys and girls, which nowadays tends to function to the detriment of boys. One long-range indicator, over the past several years, has been diminishing numbers of male college graduates in contrast to rising numbers of female college graduates. The relationship to gaming lies in widespread rejection of gaming in education, which can be seen in some aspects as a rejection of fundamental boy culture. Games are a major means of social interaction among boys in today's media-saturated environment.

In "Technologies Enabling Instructional Designers to Build Their Own Dynamically Adaptive Tutoring Systems" Joseph M. Scandura from TutorITweb.com, also a University of Pennsylvania professor emeritus, discussed the history of adaptive learning systems and then focused on TutorIT, a dynamically adaptive tutoring system that interacts with students based on what they know at various times. It is designed to interact with students in a manner similar to a human tutor, a feature that had not been achieved in earlier computermediated tutoring systems.

Rounding out the afternoon was "Informing Our Field: How We Examine, Document, and Disseminate Information About Trends and Issues in Instructional Design and Technology." Panelists discussed how best to document and report trends and issues important to the field, incorporating information from a wide variety of sources, from technology innovations to the latest breakthroughs in neuroscience research. The panelists included authors and scholars who regularly synthesize data sources to produce reports on the trends and issues that affect, define, and refine instructional design and technology practice.

Early risers on Friday participated in "Multimedia in MOOCs: Best Practices for Cultural Inclusion," led by a distinguished panel, including Thomas C. Reeves, University of Georgia; Mimi Miyoung Lee, University of Houston; Yadi Ziaee, Athens State University; and Curtis J. Bonk, Indiana University. The discussion revolved around an oftenoverlooked factor, namely cultural sensitivity, especially when MOOCs are intended for global enrollment. Panelists reviewed best practices for designing multimedia in MOOCs in ways that are culturally inclusive. Much of the session discussion summarized content in a recent book edited by the presenters, MOOCs and Open Education Around the World, published by Routledge.

Another presidential session was devoted to a new publishing venture, "AECT Major Online Reference WorkLearning, Design, and Technology: An International Compendium of Theory, Research, Practice, and Policy." The presenters included some of the prominent individuals now actively working to bring this effort to fruition, editors J. Michael Spector, Barbara Lockee, Marcus Childress, and author Katherine Cennamo. The AECT/Springer Major Reference Work (MRW) will include substantive, peerreviewed articles that examine learning theory, research, design and development, practice, and policy. The MRW will feature focused studies and reports with rich descriptions and illustrations of cases, studies, or conceptual frameworks. Works that synthesize findings across several studies and indepth reports of evaluations and policy analyses are especially sought. As this initiative develops, more information will be forthcoming. Members should be alert to future reports on the AECT website.

Two afternoon sessions rounded out the presidential strand. The first of these was "Walking in Their Footsteps (or High Heels): AECT Women Discuss the Influence of the Women Who Paved the Way." A panel discussed how women have gained positions of influence in the profession that has a tradition of the "good old boy" network. Panelists discussed the women in their own lives who have made the difference for them within AECT and in the profession.

The final presidential session was "Educational Technology and Instructional Design in East Asia: New Academic Programs and New Career Opportunities." Presenters included Meifeng Liu, Beijing Normal University; Inwoo Park, Korea University; and Katsuaki Suzuki, JSET Vice President, Kumamoto University. In East Asia many programs in educational technology have strongly emphasized teacher training 
and media production skills. However, in recent years a variety of career opportunities in the business world have become available for graduates who possess strong skills in instructional design and performance improvement. In light of these opportunities a number of graduate programs have been developed or redesigned to provide graduates with skills they will need in order to succeed as instructional design professionals in the business world. Academic leaders of three such programs in China, Japan, and South Korea, described their programs.

For members who were not able to make it to Indianapolis the major sessions were streamed live as well as captured for future viewing, and as happens annually an extensive proceedings publication will be available in due course.
Attendance at the annual gatherings has risen consistently in recent years. Nearly a thousand scholars, professionals, and students came from the Americas, Europe, Asia, and Australia to attend sessions, share information, and network with colleagues at the 2015 convention. Join this international community of participants in 2016 for the next iteration of this cutting-edge conference. The 2016 convention will be held in Las Vegas, Nevada, October 17-21.

Donovan R. Walling is a writer and editorial consultant, currently residing in Bloomington, IN. Direct correspondence regarding this column to him via email to: drwalling@gmail.com. 